\title{
Correction to: Maturation process of natural resins recorded in their thermal properties
}

\author{
Joanna Pagacz ${ }^{1, *}$ (D), Beata Naglik², Paweł $\mathrm{Stach}^{3}$, Przemysław Drzewicz ${ }^{4}$,
} and Lucyna Natkaniec-Nowak ${ }^{3}$

${ }^{1} \npreceq$ UKASIEWICZ - Institute of Ceramics and Building Materials, Ceramic and Concrete Division in Warsaw, 9 Postępu Str., 02-676 Warsaw, Poland

${ }^{2}$ Polish Geological Institute - National Research Institute, Upper Silesian Branch, 1 Królowej Jadwigi Str., 41-200 Sosnowiec, Poland

${ }^{3}$ The Faculty of Geology, Geophysics and Environmental Protection, The Department of Mineralogy, Petrography and Geochemistry, AGH University of Science and Technology, 30 Mickiewicza Av., 30-059 Kraków, Poland

${ }^{4}$ The Polish Geological Institute - National Research Institute, 4 Rakowiecka Str., 00-975 Warsaw, Poland

Published online:

10 March 2020

(C) Springer Science+Business

Media, LLC, part of Springer

Nature 2020

\section{Correction to:}

J Mater Sci (2020) 55:4504-4523.

https://doi.org/10.1007/s10853-019-04302-0

In the original article, there were errors in the Acknowledgements section. The corrected first sentence of the paragraph follows:
This study was supported by the research Grant No. 16.16.140.315 from AGH University of Science and Technology and the research Grant No. 61.9012.1908.00.0 from Polish Geological InstituteNational Research Institute.

Publisher's Note Springer Nature remains neutral with regard to jurisdictional claims in published maps and institutional affiliations.

The original article can be found online at https:/ / doi.org/10.1007/s10853-019-04302-0.

Address correspondence to E-mail: jpagacz@interia.pl

https:/ / doi.org/10.1007/s10853-020-04506-9 